\title{
Effect of fiber on the rheological properties of gelled acid
}

\author{
Bo Gou ${ }^{1}$ - Mingyong Zeng ${ }^{2} \cdot \mathrm{Kunjie} \mathrm{Wang}^{3} \cdot \mathrm{Xiao}^{\mathrm{Li}}{ }^{1} \cdot$ Jianchun Guo ${ }^{1}$
}

Received: 18 September 2020 / Accepted: 25 February 2021 / Published online: 13 March 2021

(c) The Author(s) 2021

\begin{abstract}
Degradable fiber is widely used to assist gelled acid diversion and reduce acid leak-off in the acid stimulation of carbonate hydrocarbon reservoirs in Sichuan Basin of China. The rheological properties of an acid system will affect the geometry of the acid-etching fracture. However, the effect of fiber on the rheological properties of gelled acid is not yet clear. This paper investigates the rheological properties of gelled acid with various fiber concentrations at different temperatures. The results show that when the temperature is less than the degradable temperature of the fiber, the apparent viscosity of gelled acid rises gradually with an increase in fiber concentration, while the fiber has no significant effect on the viscosity of gelled acid at the degradable temperature. The dissolution process of fiber in gelled acid experiences none-dissolution, surface dissolution, dissolution and fining, and a complete dissolution stage from low to high temperatures, which all have different effects on gelled acid viscosity. The fiber links more gelling agent molecules of gelled acid together to form a quasi-network structure between the fiber and fiber and the fiber and polymer, which results in a rise in the viscosity of gelled acid. The acid system also shows a strong shear thinning property under different temperatures and fiber concentrations. However, the power-law index $n$ of this acid system always maintains a steady average value of about 0.181 , while the change pattern of consistency index $K$ is similar to the change in viscosity with varying fiber concentrations and temperatures. The research results are useful for acid fracturing treatment design in carbonate reservoir.
\end{abstract}

Keywords Carbonate reservoir $\cdot$ Acid fracturing $\cdot$ Degradable fiber $\cdot$ Gelled acid $\cdot$ Rheological property $\cdot$ Apparent viscosity

\section{Introduction}

Marine carbonate hydrocarbon reservoirs are an important hydrocarbon resource. Recently, many deep and ultra-deep naturally fractured carbonated gas reservoirs have been found in Sichuan and China's Tarim Basin (He et al. 2019). Acid treatment is an indispensable well stimulation technology for carbonate reservoirs due to the naturally fractured, strong heterogeneity, and un-continuous sweet point of hydrocarbon (Aljawad et al. 2019).

Bo Gou

swpugb@163.com; bogou@swpu.edu.cn

1 State Key Laboratory of Oil and Gas Reservoir Geology and Exploitation, Southwest Petroleum University, Chengdu, China

2 Sinopec Southwest Oil \& Gas Company, Chengdu, China

3 Sinopec Southwest Petroleum Engineering Co. Ltd, Chengdu, China
Because the natural fracture is easily connected and etched by gelled acid for creating complex fracture network, gelled acid is widely used in the acid stimulation of marine carbonate reservoirs in Sichuan Basin (Gou et al. 2021a, b). To improve the performance of acid distribution and reduce acid leak-off in the acid stimulation process, degradable fiber is used to temporarily block natural fractures and acid-etching wormholes, which makes acid divert to another un-stimulated area to create new fractures and assists in controlling acid leak-off (Guo et al. 2015a; Zhang et al. 2020; Jauregui et al. 2011; Quevedo et al. 2012). Acid rheological properties have a large influence on fracture morphology, acid-rock reaction rate and the effective penetration distance of living acid, etching morphology and fracture conductivity, and acid leak-off (Gou et al. 2021a, 2021 b; Dong et al. 2018; Rui et al. 2018; Mou et al. 2012). Therefore, it is necessary to understand the impact of fiber on the rheological properties of gelled acid.

Degradable fiber has also been used in well stimulation (e.g., fracturing fluid with degradable fiber to improve the 
capacity of carrying proppants) of petroleum production. Many studies had reported the rheological properties of fiberassisted fracturing fluid and the effects of fiber on the rheological characterization for fracturing fluids that may not be uniform. Vasudevan et al. (2001) first reported that the addition of fiber increased the apparent viscosity of linear guar fracturing fluid and led to a three-time increment. However, it was still much lower than the borate cross-linked fracturing fluid under the same condition. Guo et al. (2015b) showed that the apparent viscosity of fiber-assisted hydroxypropyl guar fracturing fluid was affected by shear rate, fiber concentration, and temperature. Engels et al. (2004) and similarly Bulova et al. (2006) found that a small addition of fiber had no significant effect on the rheological properties of cross-linked fracturing fluid. Zhao et al. (Zhao et al. 2016) also reported that the addition of fiber had little influence on the apparent viscosity of fiber-laden cross-linked fracturing fluid.

Recent experimental work has focused on the rheology properties of fiber-assisted fracturing fluid or fiber suspension, but those fluid systems were non-reactive systems or not an acid system. During acid fracturing in carbonate reservoir, there are two types of fiber mixing ways. One way of mixing is that the fiber is mixed with fracturing fluid, slick water, and the blend is injected into the formation as a diverter stage, and then followed by acid (Guo et al. 2015a; Zhang et al. 2020). The other way is that the fiber is directly mixed with acid (Jauregui et al. 2011; Quevedo et al. 2012). Either way, fiber would be contacted and mixed with acid in the wellbore sooner or later. Therefore, it is necessary to systematically study the rheological properties of an acid system with fiber, which is indispensable to the diverting acid fracturing treatment design.

\section{Experimental research}

\section{Experimental materials and sample preparation}

The gelled acid and fiber were used in the experimental research. Table 1 shows the formula and chemical composition of gelled and fiber.

The degradable fiber, which was widely used for acid fracturing in the Sichuan Basin's marine carbonate reservoir (Fig. 1), was a polyester material with densities ranging from 1.20 to $1.30 \mathrm{~g} / \mathrm{cm}^{3}$, with a degradation temperature set at $120^{\circ} \mathrm{C}$, having a length of $6 \mathrm{~mm}$ and a diameter of $12-13 \mu \mathrm{m}$, and its chemical structure was $\mathrm{HO}-\left[\mathrm{OCR}_{1}-\mathrm{COOR}_{2}-\right]_{\mathrm{n}}-\mathrm{OH}$.

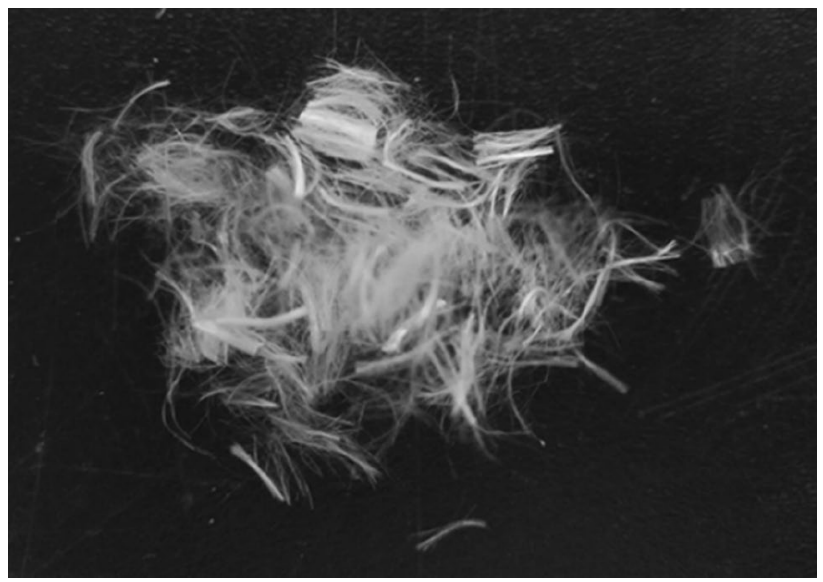

Fig. 1 Degradable fibers for acid fracturing

A degradable fiber-laden gelled acid system with uniform and stable fiber suspension fluid was prepared by performing the following steps. The fibers were dispersed slowly into the gelled acid through manual work at room temperature until the required fiber concentration was reached while the mixer was running rapidly. Lastly, the mixture was stirred slowly to obtain the homogeneous dispersion system without bringing air into the suspension. Figure 2 shows the prepared degradable fiber-laden gelled acid system with fiber concentration from 0.1 to $0.5 \mathrm{wt} \%$ in the top of view and front of view.

\section{Rheological measurement and experimental method}

A Haake Mars III rheometer concentric cylinder test system was used to test the apparent viscosity and shear thinning properties of the fiber-laden gelled acid system. The rheological properties of the acid system were measured under different fiber concentrations and temperatures ranging from 60 to $120^{\circ} \mathrm{C}$. A steady shear test was also conducted to recognize the apparent viscosity with the shear rate of $170 \mathrm{~s}^{-1}$ for $90 \mathrm{~min}$. A variable shear test was conducted to comprehend the shear thinning property with the shear rate from 0.1 to $500 \mathrm{~s}^{-1}$ in a step change pattern. The flow chart of this experiment is shown in Fig. 3.

Table 1 Experimental materials

\begin{tabular}{ll}
\hline Materials & Formula and chemical composition \\
\hline Fiber & $\begin{array}{l}0 \mathrm{wt} \%, 0.1 \mathrm{wt} \%, 0.2 \mathrm{wt} \%, 0.3 \mathrm{wt} \%, 0.4 \mathrm{wt} \%, \text { and } 0.5 \mathrm{wt} \% \text { fiber (ester polymer) } \\
\text { Gelled acid }\end{array}$ \\
$\begin{array}{c}20 \mathrm{wt} \% \mathrm{HCl}+0.8 \mathrm{wt} \% \text { gelling agent (polyacrylamide) }+0.3 \mathrm{wt} \% \text { corrosion } \\
\text { inhibitor (mannich base) }\end{array}$ \\
\hline
\end{tabular}



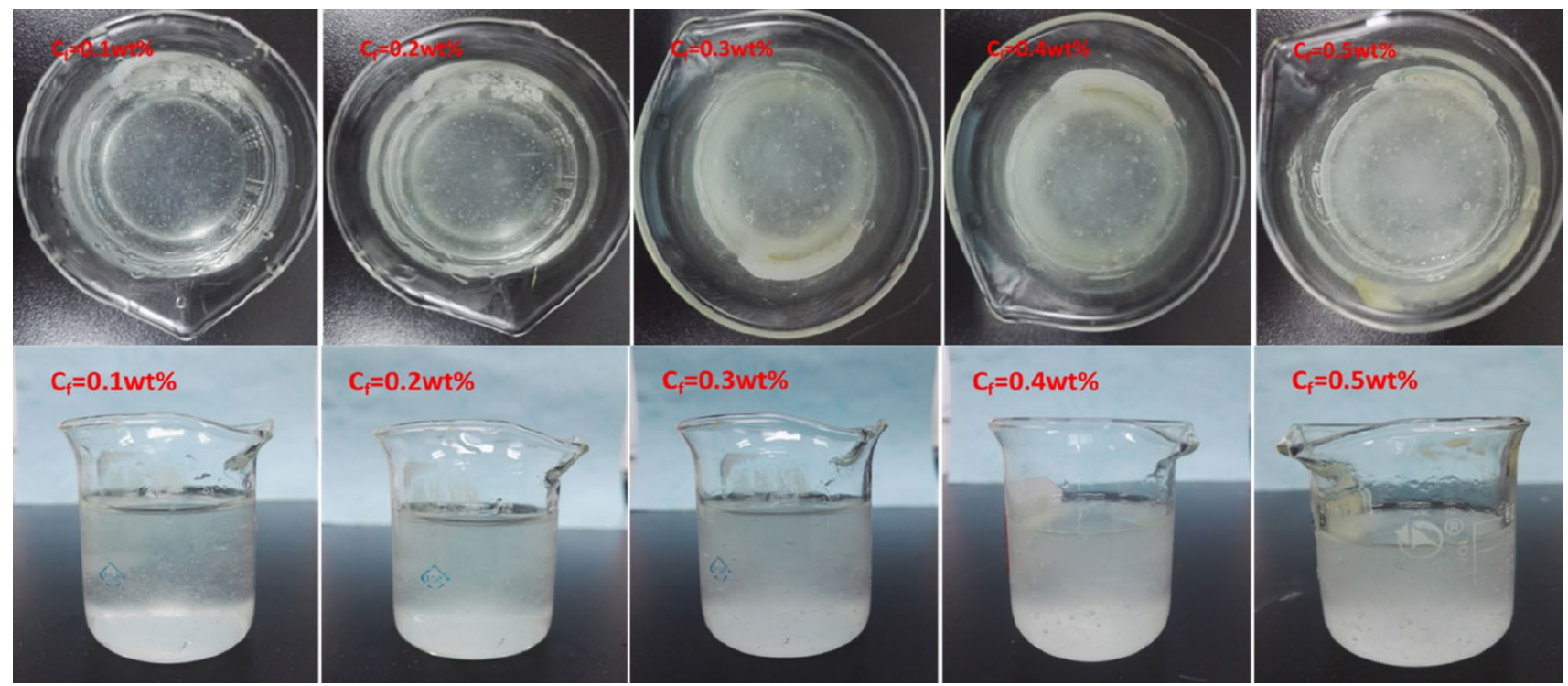

Fig. 2 Dispersion state of the fiber in the gelled acid at room temperature

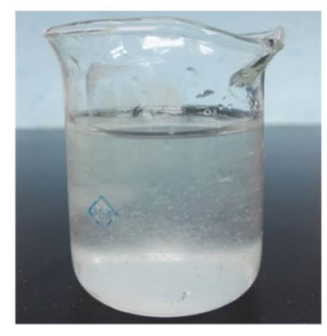

Gelled acid preparation and hydration
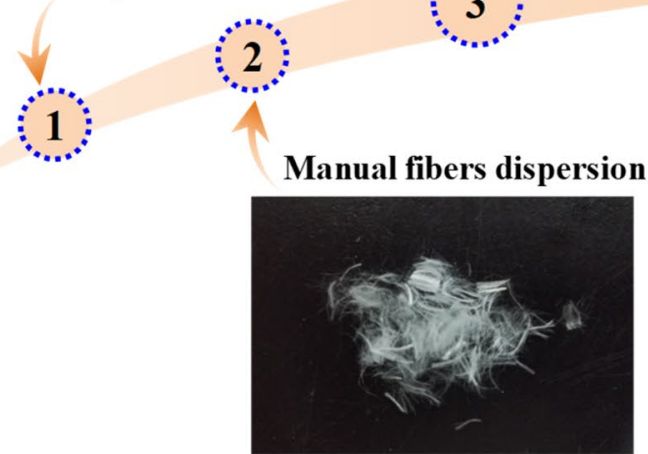

Fig. 3 Flow chart of the rheological experimental procedure

\section{Results and discussion}

\section{Effect of fiber concentration on the apparent viscosity}

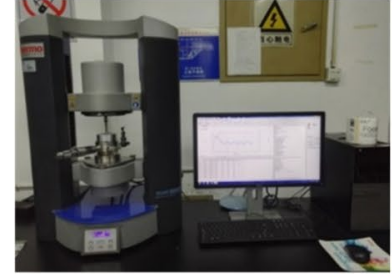

Steady and variable shear test

Gelled acid and fibers mixed

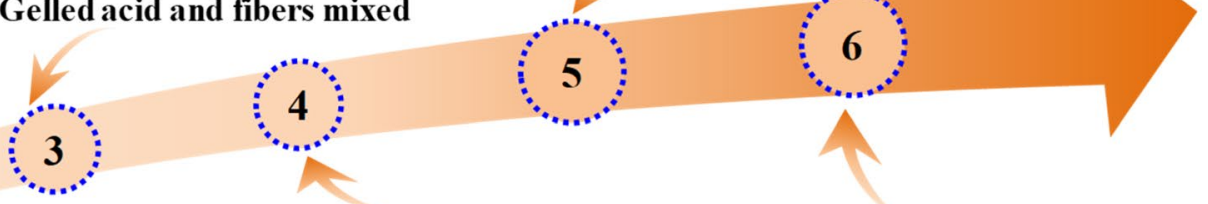

Stable fiber-laden gelled acid

Microscopic construction
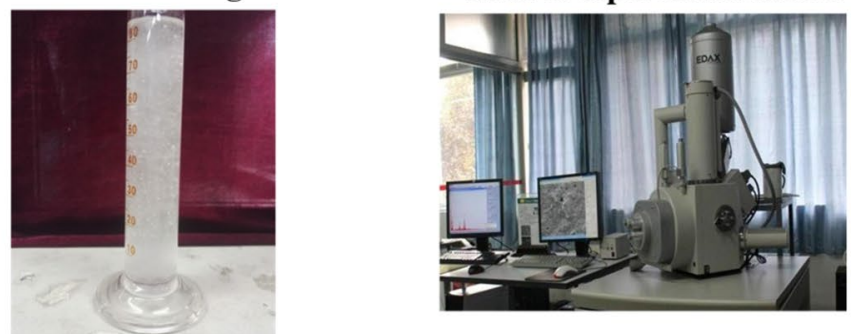

Apparent viscosity of the fiber-laden gelled acid system

Figure 4 presents the rheology curves of gelled acid and gelled acid with $0.3 \mathrm{wt} \%$ fiber at $80{ }^{\circ} \mathrm{C}$ with the fixed shear rate of $170 \mathrm{~s}^{-1}$. After $20 \mathrm{~min}$, the temperature reached 


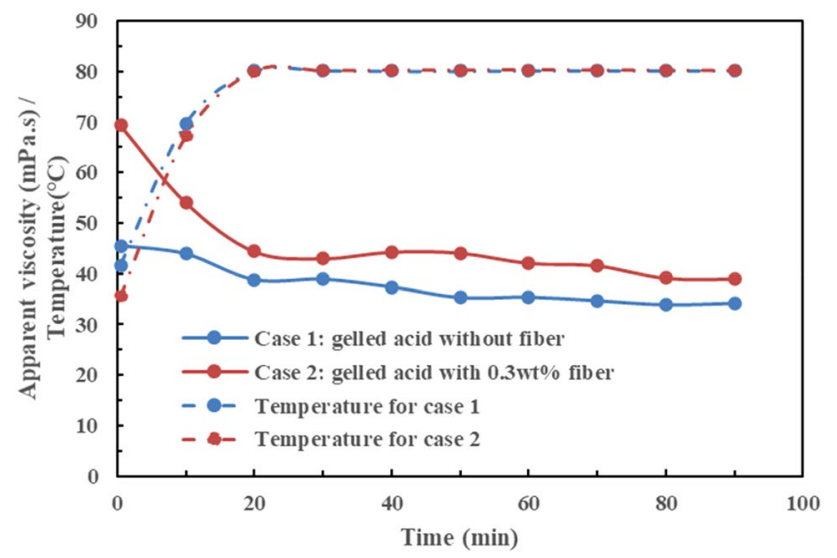

Fig. 4 Comparison of rheology curves of gelled acid and gelled acid with $0.3 \mathrm{wt} \%$ fiber

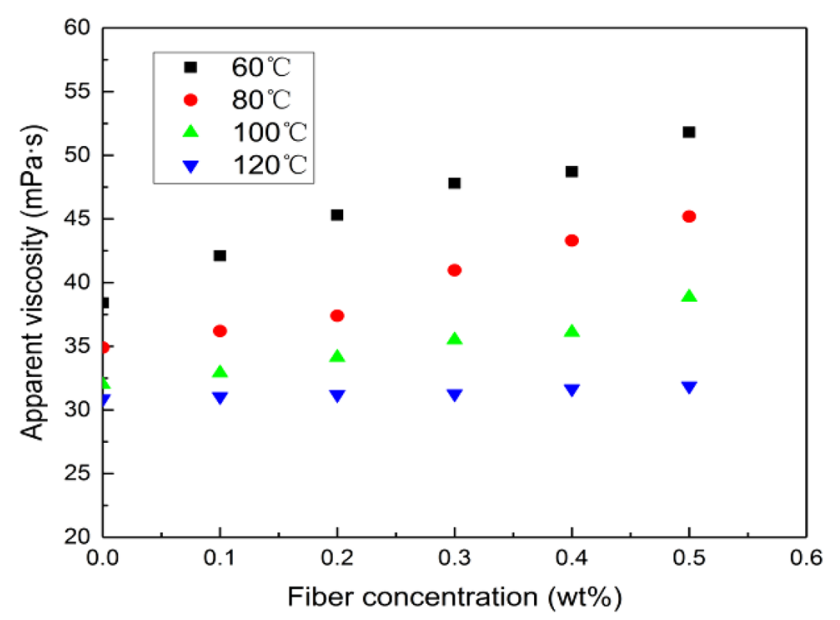

Fig. 5 Effect of fiber concentration on apparent viscosity at different temperature

experimental value at $80{ }^{\circ} \mathrm{C}$ and kept stable, while the apparent viscosity of gelled also was stayed stable and had been increased by $17 \%$ with help of fiber. We take the average of the stabilization segments on the rheological curve as the apparent viscosity of this acid system. Steady shear test showed that the apparent viscosity of the acid system maintained a relatively stable value over a period of $90 \mathrm{~min}$, which indicates that the acid system has good resistance to both shear and temperature.

Figure 5 shows that the addition of a small amount of thin flexible fibers to the gelled acid noticeably changes its rheological properties at a fixed temperature. With an increase in temperature, the apparent viscosity decreased gradually at the fixed fiber concentration. Compared with no fiber gelled acid, the apparent viscosity of the gelled acid within $0.5 \mathrm{wt} \%$ fiber was increased by $34.9 \%, 28.9 \%$, and $24.7 \%$ at temperatures of $60{ }^{\circ} \mathrm{C}, 80^{\circ} \mathrm{C}$, and $100{ }^{\circ} \mathrm{C}$, respectively, while the fiber concentration had no influence on viscosity at the degradation temperature of $120^{\circ} \mathrm{C}$ and the acid system always kept a stable viscosity at $31 \mathrm{mPa} \cdot \mathrm{s}$. It means that the fiber concentration will have a certain impact on gelled acid viscosity and that the lower the temperature, the more significant that influence will be. This finding suggests that when the formation temperature is less than $120{ }^{\circ} \mathrm{C}$, an increase in the fiber concentration could improve gelled acid viscosity, while it is helpful to retard the acid/rock reaction, reduce the acid leak-off rate, and block natural fractures (Dong et al. 2018). However, when the formation temperature is above $120^{\circ} \mathrm{C}$, this fiber does not add to the acid viscosity, and a high temperature resistant fiber will be needed for this formation. Therefore, when the reservoir temperature is greater than the degradation temperature of the fiber, it is invalid to increase the fiber dosage to improve acid viscosity, which also means that the fiber only works at temperatures lower than $120^{\circ} \mathrm{C}$.

The fiber concentration ranging from 0.1 to $0.5 \mathrm{wt} \%$ may be enough for controlling acid leak-off and reducing acid-rock reaction rate, but insufficient for creating new fracture, so the effect of extend fiber concentration should be discussed in the future. What's more, the gelled concentration is also reduced in the fracture due to acid-rock reaction, so the influence of fiber on remain acid viscosity should also be investigated in the future.

\section{Micro-morphology of the fiber-laden gelled acid system}

Analysis of the micro-morphology of fiber in gelled acid at different temperatures with fixed concentration $0.5 \mathrm{wt} \%$ in Fig. 6, shows that the gelled acid had a strong corrosion effect on fiber, which became more obvious under increasing temperatures. At an experimental temperature, the dissolution process of fiber in the gelled acid experienced a none-dissolution stage in Fig. 6 a at $60{ }^{\circ} \mathrm{C}$, a surface dissolution stage in Fig. $6 \mathrm{~b}$ at $80^{\circ} \mathrm{C}$, dissolution and fining stage in Fig. $6 \mathrm{c}$ at $100^{\circ} \mathrm{C}$, and a complete dissolution stage in Fig. $6 \mathrm{~d}$ at $120^{\circ} \mathrm{C}$. The fiber structure was quasi-network structure with rod fibers at $60{ }^{\circ} \mathrm{C}$, small rod fibers at $80{ }^{\circ} \mathrm{C}$ and hairlines fibers at $100{ }^{\circ} \mathrm{C}$, respectively, which was useful to increase the viscosity of gelled acid. The high temperature and acid corrosion have a double sustained positive effect on degradation of ester polymer fiber and fluid stability. Specially, when the temperature reached the degradation temperature of the experiment used fiber at $120{ }^{\circ} \mathrm{C}$, there was little network structure. It is foreseeable that when the fiber is degraded, the effect of the fiber on the viscosity change of the gelled acid will be significantly reduced. 

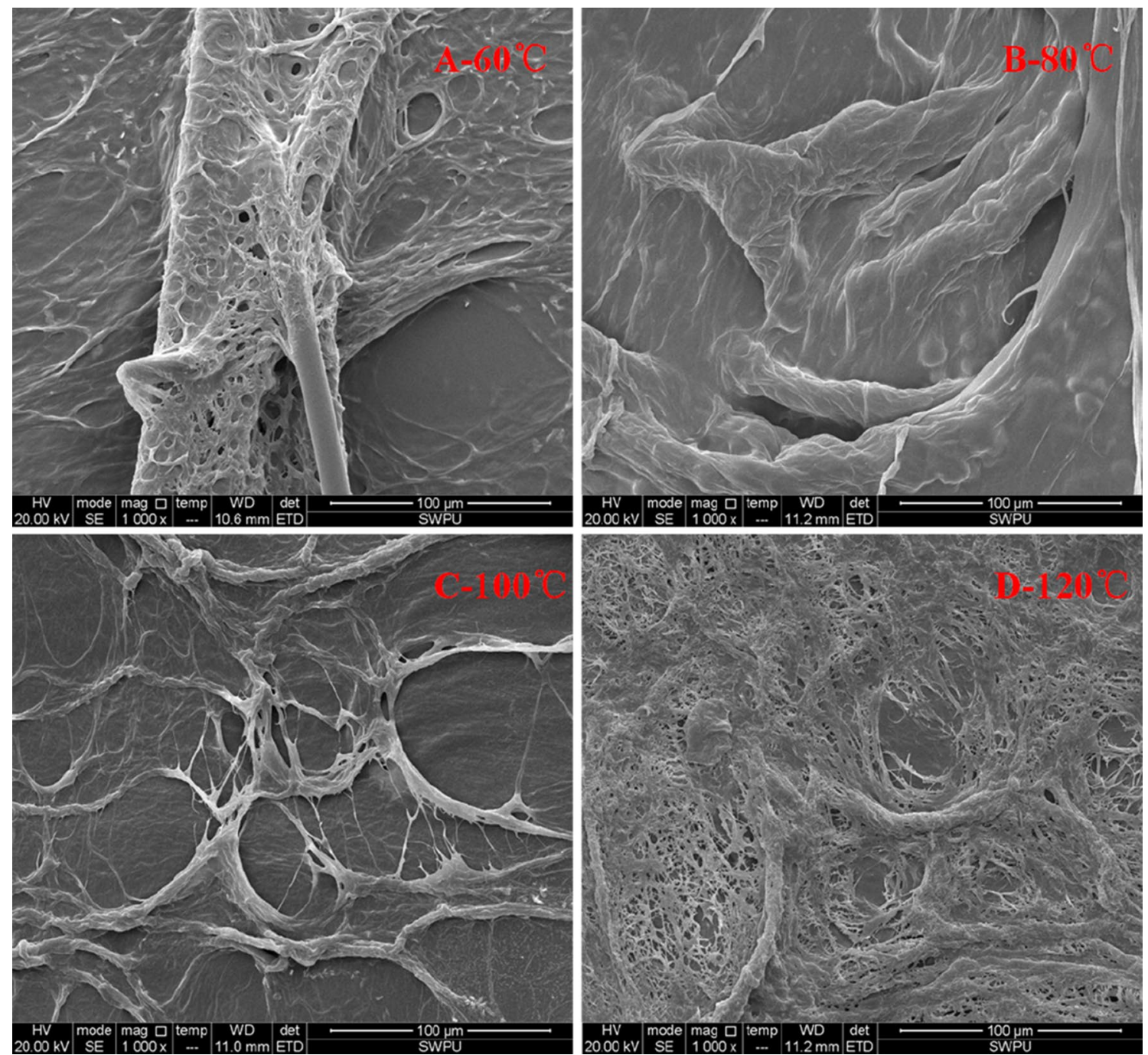

Fig. 6 Morphology of fiber in gelled acid at different temperatures (Mag 1000×)

\section{Viscosity-temperature model of the fiber-laden gelled acid system}

Many different equations have been proposed to model the viscosity of liquids. The experimental temperature ramping curves of the acid system that we used were fitted to two classical viscosity-temperature models: Frenkel-Andrade model (Andrade 1940) and power-law model (Oroian 2012).

Frenkel-Andrade model assumes that viscosity is a thermally activated process described by using the Arrhenius-type exponential relationship as follows (Ojovan 2015; Ashqer et al. 2014):

$\mu=\mu_{0} e^{(E / \mathrm{RT})}$ where $\mu_{0}$ is the pre-exponential viscosity, $E$ is the activation energy for the viscous fluid, $T$ is the temperature, and $R$ is the gas constant $8.3144 \mathrm{~J} \cdot \mathrm{mol}^{-1} \cdot \mathrm{K}^{-1}$.

The effect of temperature on the apparent viscosity of this acid system was also analyzed by using power-law model (Wong et al. 2016):

$\mu=a T^{m}$

where $\mu$ is the apparent viscosity in $\mathrm{mPa} \cdot \mathrm{s}, T$ is the temperature in ${ }^{\circ} \mathrm{C}$ and $a, m$ is a constant, respectively.

Figure 7 presents the apparent viscosity of the acid system in different fiber concentrations as a function at different temperatures, the fitted parameters of the FrenkelAndrade model, and the power-law model. 


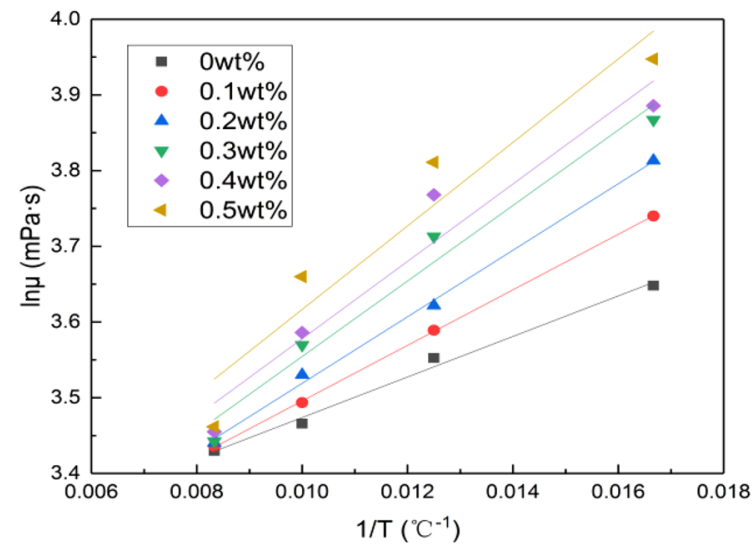

(A)

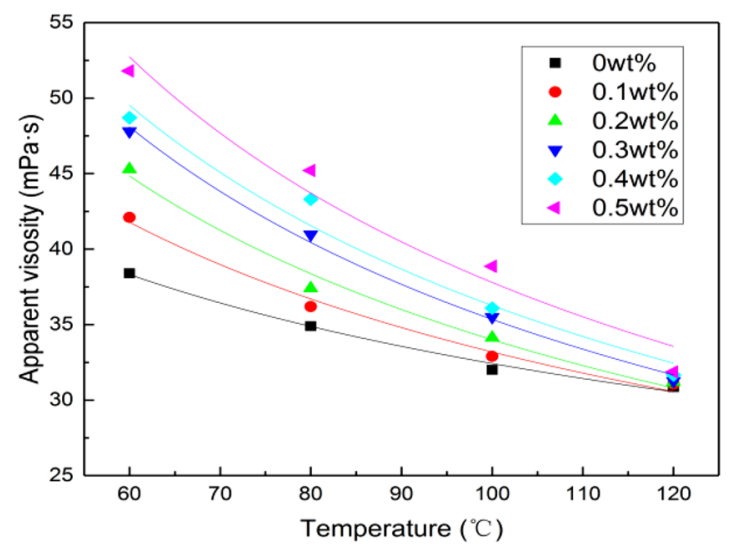

(B)

Fig. 7 Temperature ramping curves of acid in different fiber concentrations fitted to the Frenkel-Andrade viscosity-temperature model (a) and the power-law viscosity-temperature model (b)

Table 2 Fitted parameters of the Andrade's model and the power-law model

\begin{tabular}{lllllllc}
\hline $\begin{array}{l}\text { Parameters/fiber } \\
\text { concentration (wt\%) }\end{array}$ & 0 & 0.1 & 0.2 & 0.3 & 0.4 & 0.5 \\
\hline Frenkel-Andrade & $\mu_{0}$ & 24.6819 & 22.8459 & 21.7493 & 21.2356 & 21.4774 & 21.4334 \\
& $E / \mathrm{RT}$ & 26.7744 & 36.6970 & 43.9421 & 49.8743 & 51.0926 & 55.1644 \\
Power-law model & $a$ & 146.1049 & 264.5896 & 411.9974 & 567.3493 & 602.0914 & 760.0343 \\
& $m$ & -0.3269 & -0.4508 & -0.5417 & -0.6028 & -0.6101 & -0.6517 \\
\hline
\end{tabular}

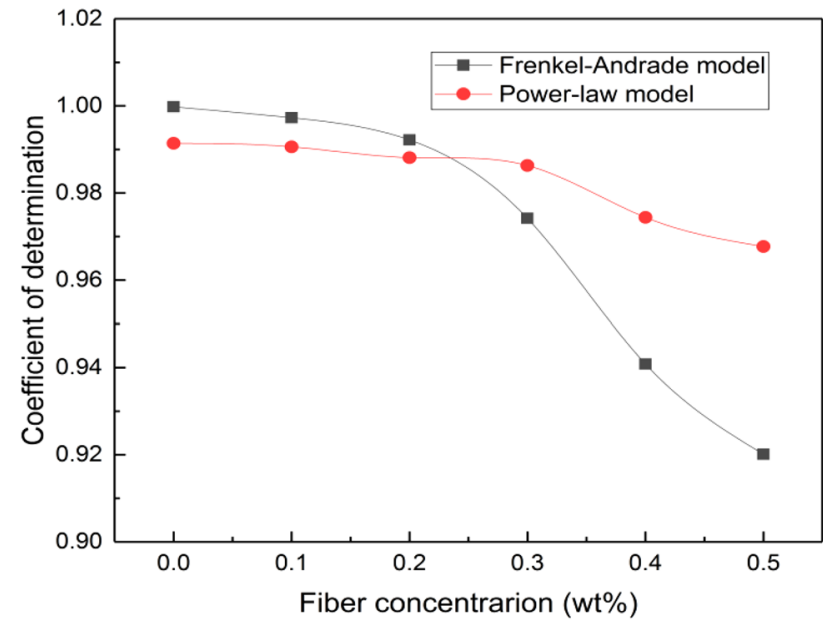

Fig. 8 Coefficients of determination with varying fiber concentrations in two different viscosity-temperature models

The fitted parameters of the Frenkel-Andrade equation and the power-law equation as a function of temperature are presented in Table 2.

Coefficients of determination for the data are above 0.92 for Frenkel-Andrade model and are above 0.95 for power-law model, which indicates a moderate fit. Figure 8 presents the coefficients of determination in the fitting for both models as a function of the fiber concentrations, which decrease with increasing fiber concentrations in the gelled acid in Fig. 5. A likely explanation is that the heat absorption by fiber degradation leads to a deviation of the relationship in terms of temperature and viscosity. This shows that the Frenkel-Andrade model could be a better fit than the power-law model when the fiber concentration is less than $0.2 \mathrm{wt} \%$. However, when the fiber concentration is more than $0.2 \mathrm{wt} \%$, the power-law model has higher coefficients of determination.

\section{Effect of fiber on the shear thinning property}

The shear thinning property of this acid was measured using a concentric cylinder test system with a controlling shear rate model. Figure 9 shows that the apparent viscosity of this acid and shear rate show a liner relationship in the double logarithmic coordinates system with the shear rate ranging from 0.1 to $500 \mathrm{~s}^{-1}$. This indicates that the rheological properties of the degradable fiber-laden gelled acid system could be described by the Ostwald-de-wale power-law model (Jabbari et al. 2016):

$\tau=K \cdot \gamma^{n}$ 


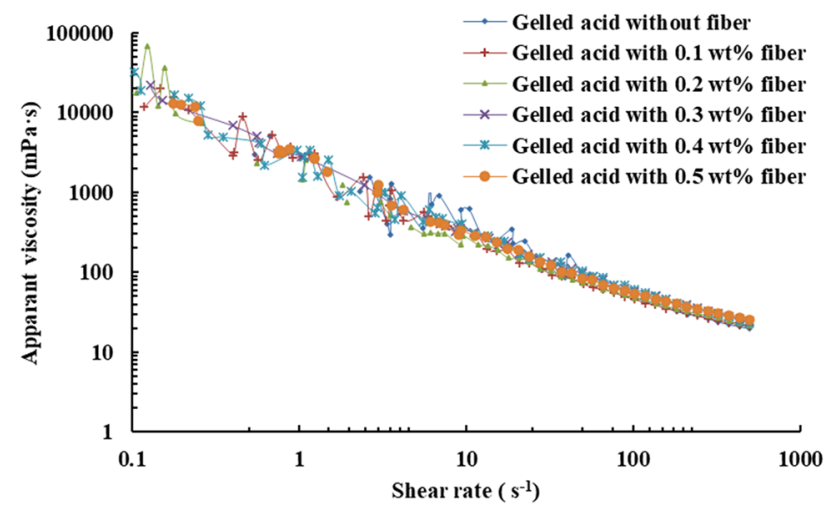

Fig. 9 Effect of shear rate on gelled acid with different fiber concentration at $80{ }^{\circ} \mathrm{C}$

$\tau=K \cdot \gamma^{n}=K \cdot \gamma^{n-1} \cdot \gamma=\mu_{a} \cdot \gamma$

where the apparent viscosity is $\mu_{a}=K \cdot \gamma^{n-1}$.

The shear viscosity and shear rate are in a liner relationship in double logarithmic coordinates as:

$\log \mu_{a}=\log K+(n-1) \log \gamma$

The data of our rheology experiment were fitted with Eq. (5). The least squares method was used to determine the power-law index $n$ and the consistency index $K$ of this acid system in the Ostwald-de-wale model. Rheological parameters are listed in Table 3. Correlation coefficients $R^{2}$ are above 0.94 , which indicates a good fit between the rheological model and our laboratory test data.

As the fiber concentrations and temperatures varied, the $n$ of the acid system kept a nearly stable average value of about 0.181 in Fig. 10, which shows that the value of $n$ had a low discrete degree characteristic with the different fiber concentrations, temperatures, strong non-Newtonian fluid characteristics, and strong shear shinning properties.

Figure 11 shows that as the temperature increased, the consistency index $K$ gradually decreased at fixed fiber

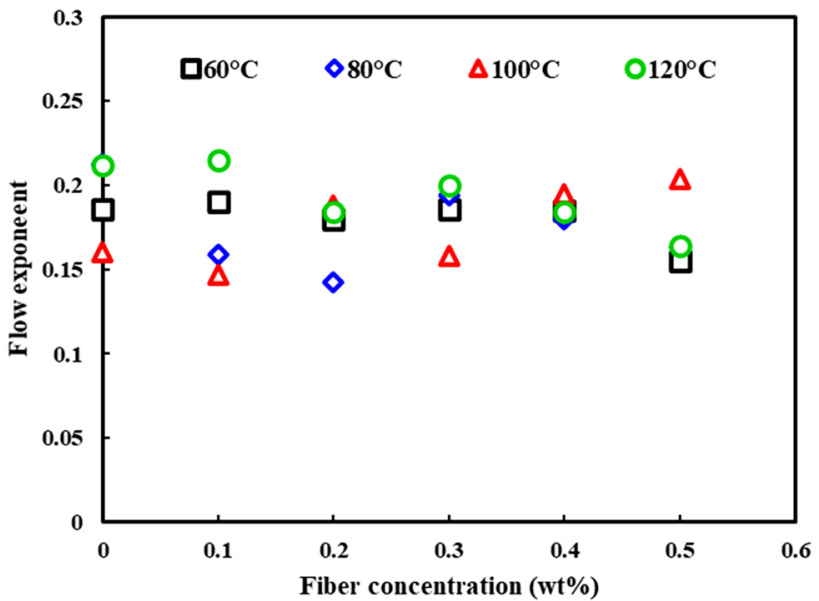

Fig. 10 Effect of fiber concentration on $n$ values under different temperatures

concentration. At temperatures below $80{ }^{\circ} \mathrm{C}, K$ declines rapidly when the fiber concentration is more than $0.2 \mathrm{wt} \%$. However, when the temperature rises to $100{ }^{\circ} \mathrm{C}$, this decreasing trend levels off. Moreover, when the fiber concentration is below $0.2 \mathrm{wt} \%, K$ has no obvious change at temperatures from 60 to $100{ }^{\circ} \mathrm{C}$. Act the fiber degradation temperature of about $120^{\circ} \mathrm{C}$, the $K$ reduces to a constant value at about $1750 \mathrm{mPa} \cdot \mathrm{s}^{\mathrm{n}}$. The fiber causes an increment of consistency index $K$ below the degradation temperature.

It is clearly that $K$ shows a fairly similar change pattern to that of the apparent viscosity with variations in fiber concentration and temperature in Fig. 5, proving that the value of $n$ would be a steady constant in different fiber concentrations and at different temperatures. Equation (3) indicates that the values of $n$ were the same at different fiber concentrations and temperatures, so the apparent viscosity would have a strong correlation with the value of $K$ of a degradable fiber-laden gelled acid system at a constant shear rate. This further validates our experimental results.
Table 3 Power-law model rheological parameter fitting results

\begin{tabular}{|c|c|c|c|c|c|c|c|c|c|c|c|c|}
\hline \multirow{2}{*}{$\begin{array}{l}\text { Fiber concen- } \\
\text { tration (wt } \%)\end{array}$} & \multicolumn{3}{|l|}{$60^{\circ} \mathrm{C}$} & \multicolumn{3}{|l|}{$80^{\circ} \mathrm{C}$} & \multicolumn{3}{|l|}{$100{ }^{\circ} \mathrm{C}$} & \multicolumn{3}{|l|}{$120^{\circ} \mathrm{C}$} \\
\hline & $K$ & $n$ & $R^{2}$ & $K$ & $n$ & $R^{2}$ & $K$ & $n$ & $R^{2}$ & $K$ & $n$ & $R^{2}$ \\
\hline 0 & 2361.0 & 0.19 & 0.96 & 2303.0 & 0.21 & 0.95 & 2134.4 & 0.16 & 0.97 & 1782.6 & 0.21 & 0.98 \\
\hline 0.1 & 2446.9 & 0.19 & 0.99 & 2345.4 & 0.16 & 0.97 & 2277.7 & 0.15 & 0.98 & 1774.2 & 0.22 & 0.95 \\
\hline 0.2 & 2865.7 & 0.18 & 0.98 & 2404.2 & 0.14 & 0.97 & 2282.2 & 0.19 & 0.98 & 1732.0 & 0.18 & 0.98 \\
\hline 0.3 & 2947.8 & 0.19 & 0.98 & 2495.0 & 0.19 & 0.99 & 2315.5 & 0.16 & 0.98 & 1773.6 & 0.20 & 0.96 \\
\hline 0.4 & 3126.4 & 0.19 & 0.98 & 2580.7 & 0.18 & 0.98 & 2401.1 & 0.20 & 0.97 & 1726.4 & 0.18 & 0.97 \\
\hline 0.5 & 3523.7 & 0.16 & 0.99 & 2618.5 & 0.16 & 0.98 & 2095.5 & 0.20 & 0.98 & 1700.0 & 0.16 & 0.97 \\
\hline
\end{tabular}

$* K$ - $\mathrm{mPa} \cdot \mathrm{sn}$ 


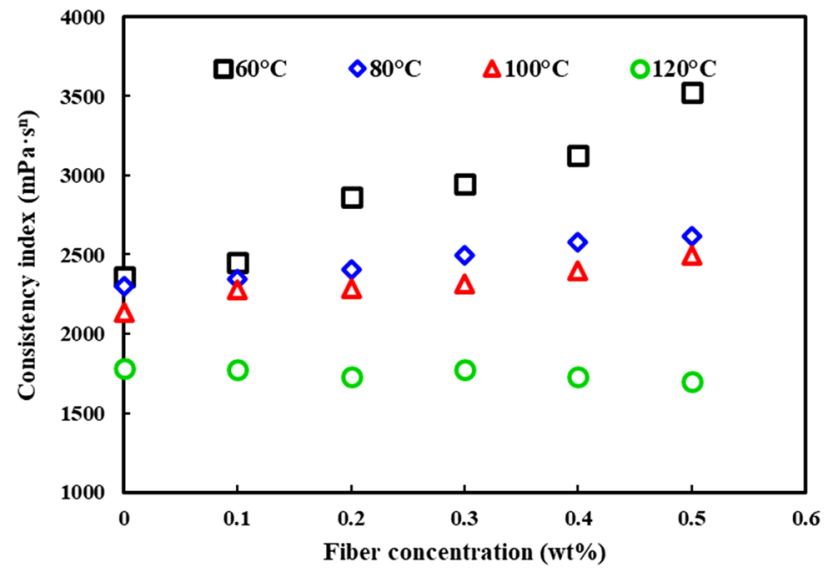

Fig. 11 Effect of fiber concentration on $K$ values under different temperatures

\section{Conclusions}

In this paper, we experimentally study the influence of fiber on the apparent viscosity and shear thinning properties of a gelled acid system under different temperatures. Two viscosity-temperature models were used to match the relationship between the apparent viscosity and the experimental temperature data. The following conclusions could be drawn:

(1) The apparent viscosity of the gelled acid and gelled acid with fibers systems maintains a stable value at a shear rate of $170 \mathrm{~s}^{-1}$ in $90 \mathrm{~min}$, which shows that the acid system has a good resistance to both shear and temperature.

(2) At temperatures of $60{ }^{\circ} \mathrm{C}, 80{ }^{\circ} \mathrm{C}$, and $100{ }^{\circ} \mathrm{C}$, an increase in fiber concentration gradually increases the apparent viscosity of the acid system, while the increment of the apparent viscosity decreases with a rise in the experimental temperature. At the degradation temperature of the fiber about $120{ }^{\circ} \mathrm{C}$, fiber has no significant effect on the apparent viscosity. However, when the formation temperature is below the degradation temperature of the fiber, an increase in the fiber concentration could improve acid viscosity. And, when the formation temperature is above the degradation temperature, it is invalid to increase the fiber dosage to improve acid viscosity.

(3) Dissolution process of fiber in the gelled acid experienced a none-dissolution stage, a surface dissolution stage, dissolution and fining stage, and a complete dissolution stage with increase of temperatures, which have different effects on the viscosity of the gelled acid.

(4) The reason for the increase in viscosity of degradable fiber-laden gelled acid system is that the fiber link more gelling agent molecules together to form a quasi- network structure between the fiber and fiber and the fiber and polymer.

(5) Rheological model of the degradable fiber-laden gelled acid system is not changed by fiber and still obeys the power-law fluid's characteristic for acid systems.

(6) Different fiber concentrations and temperatures have no significant effect on the power-law index $n$. When the temperature is less than $120^{\circ} \mathrm{C}$, the consistency index $K$ shows a rising trend as fiber concentration increases. At the degradation temperature of fiber, $K$ tends to be a stable value at around $1750 \mathrm{mPa} \cdot \mathrm{s}^{\mathrm{n}}$ in different fiber concentrations. An increase in temperature will decrease the consistency index $K$, which shows a highly similar change pattern with the apparent viscosity as fiber concentrations and temperatures change.

Funding This study was supported by the Open Fund of State Key Laboratory of Oil and Gas Reservoir Geology and Exploitation (Southwest Petroleum University) (No. PLN201608), and Sichuan Postdoctoral Special Fund (No.864).

Open Access This article is licensed under a Creative Commons Attribution 4.0 International License, which permits use, sharing, adaptation, distribution and reproduction in any medium or format, as long as you give appropriate credit to the original author(s) and the source, provide a link to the Creative Commons licence, and indicate if changes were made. The images or other third party material in this article are included in the article's Creative Commons licence, unless indicated otherwise in a credit line to the material. If material is not included in the article's Creative Commons licence and your intended use is not permitted by statutory regulation or exceeds the permitted use, you will need to obtain permission directly from the copyright holder. To view a copy of this licence, visit http://creativecommons.org/licenses/by/4.0/.

\section{References}

Aljawad M, Aljulaih H, Mahmoud M et al (2019) Integration of field, laboratory, and modeling aspects of acid fracturing: a comprehensive review. J Pet Sci Eng 181:106158

Andrade ENDC (1940) The viscosity of liquids. In: Proceedings of the royal society a mathematical physical and engineering sciences 215 (1120): 36-43

Ashqer I, Bahti A, Musameh S (2014) Rheological properties for olive oil in Palestine, Mater Sci

Bulova MN, Nosova KE, Willberg DM (2006) Benefits of the novel fiber-laden low-viscosity fluid system in fracturing low-permeability tight gas formations SPE 102956

Dong K, Zhu D, Hill AD (2018) Mechanism of wormholing and its optimal conditions: a fundamental explanation. J Petrol Sci Eng 169:126-134

Engels JN, Martinez E, Fredd CN, et al. (2004) A mechanical methodology of improved proppant transport in low-viscosity fluids: application of a fiber-assisted transport technique in East Texas [C] SPE 91434 
Gou B, Zhan L, Guo J et al (2021b) Effect of different types of stimulation fluids on fracture propagation behavior in naturally fractured carbonate rock through CT scan. J Pet Sci Eng 201:108529

Gou B, Guan C, Li X et al (2021a) Acid-etching fracture morphology and conductivity for alternate stages of self-generating acid and gelled acid during acid-fracturing. J Pet Sci Eng 200:108358

Guo J, Gou B, Yu T (2015a) Novel completions increase horizontal well production. Oil Gas J 113(4):60-65

Guo J, Ma J, Zhao Z et al (2015b) Effect of fiber on the rheological property of fracturing fluid. J Nat Gas Sci Eng 23(21):356-362

He D, Ma Y, Bo B et al (2019) Main advances and key issues for deep-seated exploration in Petroliferous Basins in China. Earth Sci Front 26(1):1-12

Jabbari M, Spangenberg J, Hattel JH (2016) Particle migration using local variation of the viscosity (LVOV) model in flow of a NonNewtonian fluid for ceramic tape casting. Chem Eng Res Des 109:226-233

Jauregui JAL, Malik AR, Garcia WN, et al. (2011) Successful application of novel fiber laden self-diverting acid system during fracturing operations of naturally fractured carbonates in Saudi Arabia, SPE 142512

Mou J, Zhang S, Zhang Y (2012) Acid Leakoff mechanism in acid fracturing of naturally fractured carbonate oil reservoirs. Transp Porous Media 91(2):573-584

Ojovan MI (2015) Viscosity and glass transition in amorphous oxides. Adv Condens Matter Phys 201:1-24

Oroian M (2012) Physicochemical and rheological properties of romanian honeys. Food Biophys 7(4):296-307
Quevedo M, Tellez F, Torres TR, et al. (2012) An innovative solution to optimizing production in naturally fractured carbonate reservoirs in Southern Mexico, SPE152554

Rui Z, Guo T, Feng Q, Qu Z, Qi N, Gong F (2018) Influence of gravel on the propagation pattern of hydraulic fracture in the Glutenite reservoir. J Petrol Sci Eng 165(6):627-639

Vasudevan S, Willberg DM, Wise JA (2001) Field test of a novel low viscosity fracturing fluid in the lost Hills Field, California SPE 68854

Wong PCH, Heng PWS, Chan LW (2016) Viscosity-temperature relationship of lipid-based excipients amenable for spray congealing: derivation of a rheological parameter with good correlation to particle size. Eur J Lipid Sci Technol 118(7):1062-1073

Zhang L, Zhou F, Feng W, Pournik M, Li Z (2020) Experimental study on plugging behavior of degradable fibers and particulates within acid-etched fracture. J Pet Sci Eng 185:0920-4105

Zhao Z, Ma J, Guo J et al (2016) Experimental investigation of rheological properties of fiber-laden crosslinked fracturing fluids. J Nat Gas Sci Eng 32:28-34

Publisher's Note Springer Nature remains neutral with regard to jurisdictional claims in published maps and institutional affiliations. 